\title{
Optimized Biodiesel Preparation from Waste Cooking Oil as a Fuel for Unmodified Diesel Engines
}

\section{DOI : 10.36909/jer.ICETET.14989}

\author{
Parvesh Kumar*1,2, M. Ramprasad $^{1}$, Sidharth $^{2,3}$ \\ 1 Mechanical Engineering Department, Vaagdevi College of Engineering, Warangal \\ 2 CASRAE, Delhi Technological University, Delhi \\ 3 Department of Mechanical and Automation Engineering, Maharaja Agrasen Institute of \\ Technology, Delhi, India \\ Corresponding Author Email - pkkhatkar12@gmail.com,
}

\begin{abstract}
The continuous fluctuation in the price of crude oil in the international market during the Covid-19 situation forced all the nation to work for self-sustainability in the energy sector. This pandemic condition also teaches all to utilize available sources effectively. So to deal with dual problems the optimized conversion of waste into an energy source is the most effective solution. In the present work waste cooking oil is converted into biodiesel and the production process is optimized using the response surface methodology technique. The central composite design approach of RSM is selected for optimization in the present work which provides a better result in limited experiments. The yield of waste cooking oil biodiesel is optimized through four parameters i.e. catalyst concentration, temp., time, and alcohol to oil molar ratio. The effect of all these parameters is analyzed exhaustively with the help of design expert software. The physicochemical properties of optimized WCOB are measured and the results are compared with petrodiesel fuel and normally prepared WCOB. It is found that the yield of WCOB is increased by more than $4 \%$ while prepared with optimized parameter values. The physicochemical properties of optimized WCOB were also found better as compared to normally prepared WCOB and comparable to petrodiesel. Hence it can be concluded that the optimization of biodiesel production not only improves the yield but also improves the quality of the biodiesel.
\end{abstract}

Keywords: RSM; waste cooking oil; optimization; central composite design; transesterification. 


\section{INTRODUCTION}

Copious and inexpensive energy is the biggest necessity of the present generation. The economic growth and industrialization expansion of the country depend upon the sources of energy available and the kind of technology used. However, most developing countries heavily dependent on imports of energy sources (Sonthalia \& Kumar, 2019). They spend a big part of their annual budget on importing these energy sources. India imports around 70$80 \%$ of its crude oil to fulfill its energy requirement (British Petroleum, 2019; P. Kumar \& Kumar, 2016). Therefore the utilization of energy sources in a proper manner is also a very important task and for that waste, management planning is very crucial. However, many researchers are working in search of an alternative to petroleum diesel as the consumption of petrodiesel is almost four times that of gasoline (Pali, Kumar, \& Alhassan, 2015). The alternatives fuels for petrodiesel such as biodiesel, alcohols with additives, gaseous fuels become very popular.

However, among all the popular options biodiesel is gaining more attention due to its properties and method of production. Biodiesel is a long chain of fatty acid alkyl esters which generally produced by the transesterification process (M. Kumar \& Sharma, 2016). In the transesterification process triglycerides are react with alcohols in presence of catalysts which enhance the reaction rate however, catalysts are not necessary for biodiesel production. After reaction with alcohols, the triglycerides are converted into a long chain of fatty acid alkyl esters which is famously known as biodiesel (Demirbas, 2009, 2010; Karthikeyan, Renganathan, \& Baskar, 2017). The biodiesel can be produced from any vegetable oil (edible and non-edible), animal fat, waste cooking oil, waste lubricating oil, etc. through the transesterification process (Knothe \& Razon, 2017; M. Kumar \& Sharma, 2016; P. Kumar \& Kumar, 2019; Raheman \& Phadatare, 2004). Biodiesel is recognized as a green alternative to petrodiesel due to its renewability, lower tailpipe emissions, and production. Apart from that, it also decreases the dependency on fossil fuels (Rosa, Tropecêlo, Caetano, \& Castanheiro, 2015). 
The most used feedstocks for biodiesel productions are vegetable oils (both edible and nonedible) and animal fats. In countries like India, biodiesel cannot be produced from edible oils as it can cause food scarcity in the country. However, a big lot of used cooking oil is dumped into the sewerage or in open land by a large number of restaurants that follow the government and FSSAI norms. This causes serious air pollution, blockage of sewerage lines, and decrease the fertility of the soil (Naveen Kumar \& Sidharth, 2018; Sidharth \& Kumar, 2019). This problem can be solved by converting waste cooking oil into biodiesel. The Government of India also identify this problem and find the same solution to overcome it, so the government decides to blend $5 \%$ of biodiesel in petrodiesel, and this biodiesel is mainly produced from waste cooking oil. So in the latest announcement of the government of India, a subsidy will be given to the investors who produce biodiesel from waste cooking oil. This increases the interest of researchers and investors in biodiesel production from waste cooking oil. However, their major concern is the final price of the waste cooking oil biodiesel (WCOB). The production cost of biodiesel is dependent upon two components; the first is the cost of feedstock and the second is the cost of production. The cost of feedstock remains fixed but the cost of production can be decreased through the optimization process which will decrease the overall cost of the biodiesel. The cost of feedstock is very less if waste cooking oil is used for biodiesel production in such case the main factor which decides the final cost of biodiesel is its production cost. In the present study, the biodiesel production process for waste cooking oil is optimized and the overall cost of the biodiesel is reduced. The response surface methodology (RSM) optimizing technique is used to optimize the biodiesel production process in the present study (Bellotti, Cassettari, Mosca, \& Magistri, 2019; Verma \& Sharma, 2016). The parameters selected to optimize the yield of biodiesel are catalyst concentration, reaction temperature, alcohols to oil molar ratio, and reaction time. All the parameters directly or indirectly affect the final production cost of biodiesel.

Increasing the catalyst concentration may or may not increase the reaction rate after a certain level but it increases the production cost of biodiesel. The same condition is applicable for the 
alcohol to oil molar ratio. These two parameters directly affect the overall production cost of biodiesel. The other two parameters i.e. reaction time and reaction temperature also affect the overall production cost of biodiesel indirectly. To maintain higher temperature and to continue reaction for longer time consuming extra energy which is also one hand of expenses. Therefore all these parameters are optimized in the present research and some important finding are concluded. The waste cooking oil is filtered with filter papers and its free fatty acid content is reduced to less than $2 \%$ through the esterification process. The transesterification process is performed afterward in which the condition central composite design (CCD) approach of the RSM technique is adopted for optimization. The range of various parameters is selected after an exhaustive literature survey and various experiments performed earlier. The complete process with detailed information, range of all parameters, and change in yield is explained in this article.

\section{LITERATURE REVIEW}

A large number of work has been conducted on the process optimization of biodiesel production with various feedstocks and different optimization techniques. The most used optimization techniques for biodiesel production are Taguchi and response surface methodology. All the methods are identify effective in optimizing the various parameters for biodiesel production but all have a different type of approach and difficulties. Therefore, an easy and accurate method is very important to be identified before starting the work. In this section, the literature survey is done to identify the most suitable method to optimize biodiesel production.

Dinkar \& Deep (Dinkar \& Deep, 2019) optimized the soybean biodiesel production process by using the antlion technique which is one of the latest techniques of optimization. The antlion technique is based on the hunting technique and approach of antlions (Mirjalili, 2015). The optimization problem is nonlinear and the yield of biodiesel is optimized by considering three variables named catalyst concentration, the temperature of the reaction, and methanol to oil molar ratio. As per the research, a set of 17 experiments were conducted for optimization. 
To perform the optimization with three variables the Taguchi gives 9 experiments and RSM allot 20 experiments (Saravanakumar, Avinash, \& Saravanakumar, 2016). The basic mode of antlion technique i.e. ants' random walk around is selected for that research. As per the author's observation the yield of $97.443 \%$ was obtained which is higher than all other optimization methods (Dinkar \& Deep, 2019).

Saravanakumar et al. (Saravanakumar et al., 2016) used Taguchi's approach to optimized the yield of Pongamia biodiesel. The author claim that the yield of $86 \%$ can be achieved if the transesterification process is performed at $550 \mathrm{rpm}$ for $80 \mathrm{~min}$ and in $\mathrm{NaOH}$ quantity of $15 \mathrm{~g}$. The author uses the L9 parameter design approach of Taguchi's technique. According to the author, the technique is simplest and the number of the experiment need to be conducted are also less as compared to other optimization methods. A similar kind of observation about Taguchi's technique are observed by Chaudhary \& Gakkhar (Chaudhary \& Gakkhar, 2019) and Kumar et al. (N. Kumar, Mohapatra, Ragit, Kundu, \& Karmakar, 2017)

P. Kumar \& Kumar (P. Kumar \& Kumar, 2019) optimized the yield of orange peel oil biodiesel using the CCD approach of the RSM technique. The authors found the RSM technique most reliable and simple to use for biodiesel production. The authors find that the experiments suggested by the RSM are more in number as compare to Taguchi's method but it is very accurate and pins the best available solution. The yield obtained is also higher than Taguchi's method. The authors claim that the yield of $97.2 \%$ can be obtained while converting orange peel oil to biodiesel. Similar results are obtained by other authors as well when used the RSM technique for biodiesel optimization (Bellotti et al., 2019; Ghadge \& Raheman, 2006; Verma \& Sharma, 2016).

\section{MATERIALS AND METHODOLOGY}

The biodiesel of waste cooking oil is prepared in the present research which is collected from the cafeteria of Vaagdevi College of Engineering (VCE), Warangal and KFC, Hanamkonda, Telangana. The other chemical is purchased from the local market of Warangal. The chemicals used for biodiesel production are of laboratory grade and $99 \%$ pure. The chemicals 
used for biodiesel production are Methanol, potassium hydroxide $(\mathrm{KOH})$, Para Toluene Sulfonic Acid (PTSA), Phenolphthalein indicator, $\mathrm{KOH}$ with normality 0.1. All the experiments of biodiesel production are performed in the Mechanical Engineering Department of VCE, Warangal. The waste cooking oil has numerous soluble and insoluble impurities in it therefore, the oil is pre-treated and filter before proceeding for biodiesel production. The collected oil is first filtered with filter paper of pore size of $40-50 \mu \mathrm{m}$. After that, the oil is heated to a temperature of 70 to $100^{\circ} \mathrm{C}$ which decrease the viscosity of oil and then filter again through the filter paper of pore size $2 \mu \mathrm{m}$. These two filtration steps remove most of the solid food impurities present in the oil. The filtered oil is then put for centrifugation for 15-20 min. During the centrifugation process, the impurities which have higher density are settled down at the bottom of the tube due to higher centrifugal force and pure oil remains at the top of the tube. The oil is then taken out from the tube and this oil is now ready for biodiesel production.

The oil is heated to above $110^{\circ} \mathrm{C}$ for 20 to $30 \mathrm{~min}$ to remove all the moisture content present in the oil. The free fatty acid content of the oil was checked afterward. The FFA of oil is checked by the titration process as followed by P. Kumar \& Kumar (P. Kumar \& Kumar, 2016). The FFA of waste cooking oil comes at $9.3 \%$ which is quite higher for the direct transesterification process. So the FFA of the oil needs to be reduced before performing the transesterification process to avoid saponification. The esterification processed adopted to reduce FFA in the present work is similar to what was followed by P. Kumar \& Kumar (P. Kumar \& Kumar, 2016). The FFA of the waste cooking oil is reduced to $1.6 \%$ from $9.3 \%$ and this is enough low to proceed for transesterification process.

The transesterification process performed in the present work is nearly similar to what is followed by P. Kumar \& Kumar (P. Kumar \& Kumar, 2019). To perform optimization of transesterification process a $200 \mathrm{ml}$ three-neck flat bottom flask is used. Each run of the experiment is performed with a $100 \mathrm{ml}$ oil sample. The oil is poured into the flask and the flask is kept on a magnetic steerer which has an inbuilt heating plate. One small size 
magnetic bit is put into the flask for continuous agitation. The agitation speed 300rmp during the transesterification process. One neck of the flask is fixed for the thermometer which is touching the oil. The neck is perfectly closed with one closer made up of dense rubber. The middle neck of the flask is connected to the condenser to reduce the evaporative loss of methanol (P. Kumar \& Kumar, 2019). The third and last neck of the flask is kept free for pouring the solution of catalyst and methanol. This neck is also closed with the help of removable airtight rubber. The flow chart of the transesterification process followed in the present work is given in fig. 1. The waste cooking oil biodiesel (WCOB) is prepared normally starting with catalyst concentration of $1 \%$, methanol to oil molar ration of 1:9, reaction temperature of $60^{\circ} \mathrm{C}$ and reaction time of 90 minutes. The yield obtained at this condition is $83 \%$ which is quite good for any transesterification process. However, the parameters can be optimised to maximise the yield. The optimisation of transesterification is performed with parameters: catalyst concentration, time, temp. \& methanol to oil molar ratio. The range of these parameters is taken after performing the experiments and information gathered from the literature survey. The range of all parameters is given in table 1 .

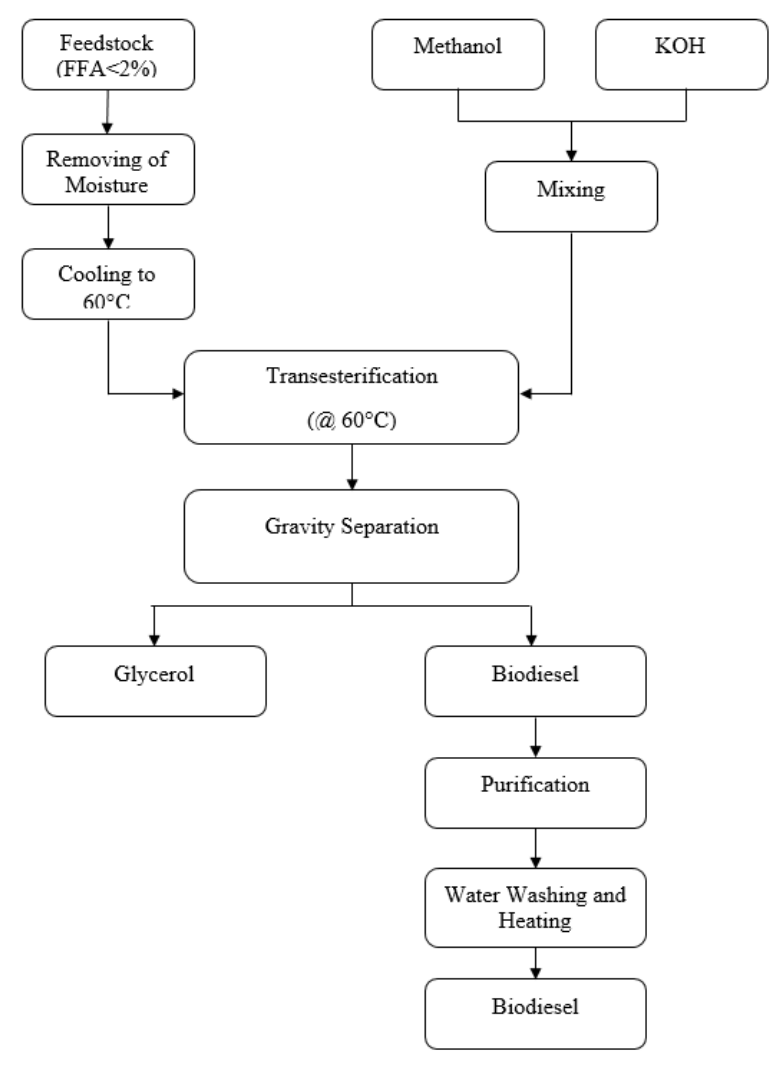


Fig. 1: Flow chart of transesterification process followed in present work.

The research surface methodology (RSM) tool is used for the optimization process. All these ranges of parameters are put in the design expert software. The approach followed for optimization is the central composite design (CCD) of RSM which suggests a total of 30 experiments to establish the relationship among all the parameters to maximize the yield. The formulas used for giving 30 sets of the experiment is $\mathrm{N}=2^{\mathrm{C}}+2 \mathrm{C}+\mathrm{N}_{\mathrm{o}}$, where $\mathrm{C}$ is independent variables which is 4 in the present study and $\mathrm{N}_{\mathrm{o}}$ is repeated experiment suggested by software randomly and 6 for the present research. All these experiments are performed in sequence wise and the results of yield obtained after all runs are put in the software. The software analyses the results and gives a final combination of all parameters with suggested maximum yield. In the end, the suggested experiment is performed and the result is compared with the software's result. Detailed information about the optimization result is given in the result and discussion session. The suggested list of 30 experiments is shown in table 2 .

Table 1:Process parameters with their ranges for transesterification Process

\begin{tabular}{|c|c|c|c|c|}
\hline Name of Parameter & Notation & Units & Low Level & High Level \\
\hline Catalyst concentration & A & $\%(\mathrm{w} / \mathrm{w})$ & 0.5 & 1.5 \\
\hline Temperature & B & ${ }^{\circ} \mathrm{C}$ & 40 & 60 \\
\hline Time & C & Min & 30 & 90 \\
\hline Molar Ratio & D & & 3 & 9 \\
\hline
\end{tabular}

Table 2: Design matrix for transesterification Process

\begin{tabular}{|c|c|c|c|c|}
\hline Run & $\begin{array}{c}\text { A: Catalyst concentration } \\
(\mathbf{w} / \mathbf{w})\end{array}$ & $\begin{array}{c}\text { B: Temperature } \\
(\mathbf{0} \mathbf{C})\end{array}$ & $\begin{array}{c}\text { C: Time } \\
(\mathbf{m i n})\end{array}$ & $\begin{array}{c}\text { D: Molar } \\
\text { Ratio }\end{array}$ \\
\hline 1 & 1 & 55 & 60 & 6 \\
\hline 2 & 1 & 55 & 120 & 6 \\
\hline 3 & 0 & 55 & 60 & 6 \\
\hline 4 & 1 & 75 & 60 & 6 \\
\hline 5 & 1.5 & 65 & 30 & 3 \\
\hline 6 & 1 & 55 & 60 & 6 \\
\hline 7 & 0.5 & 65 & 90 & 9 \\
\hline 8 & 1.5 & 65 & 90 & 9 \\
\hline 9 & 1 & 55 & 60 & 6 \\
\hline 10 & 0.5 & 65 & 90 & 3 \\
\hline 11 & 1.5 & 65 & 30 & 9 \\
\hline 12 & 2 & 55 & 60 & 6 \\
\hline 13 & 1 & 55 & 60 & 6 \\
\hline
\end{tabular}




\begin{tabular}{|c|c|c|c|c|}
\hline 14 & 1.5 & 45 & 90 & 3 \\
\hline 15 & 1.5 & 45 & 30 & 9 \\
\hline 16 & 0.5 & 45 & 90 & 3 \\
\hline 17 & 1 & 55 & 0 & 6 \\
\hline 18 & 1.5 & 65 & 90 & 3 \\
\hline 19 & 0.5 & 45 & 30 & 9 \\
\hline 20 & 0.5 & 65 & 30 & 9 \\
\hline 21 & 0.5 & 45 & 90 & 9 \\
\hline 22 & 1 & 55 & 60 & 12 \\
\hline 23 & 1.5 & 45 & 90 & 9 \\
\hline 24 & 1 & 55 & 60 & 0 \\
\hline 25 & 1 & 55 & 60 & 6 \\
\hline 26 & 1 & 55 & 60 & 6 \\
\hline 27 & 1.5 & 45 & 30 & 3 \\
\hline 28 & 1 & 35 & 60 & 6 \\
\hline 29 & 0.5 & 65 & 30 & 3 \\
\hline 30 & 0.5 & 45 & 30 & 3 \\
\hline
\end{tabular}

\section{RESULTS AND DISCUSSIONS}

The optimization of biodiesel production is a very effective tool for cost reduction and comparatively higher yield, especially for large-scale production. A small reduction in any factor changes the profit on a large scale. As discussed earlier Government of India is very serious about biodiesel production from waste cooking oil. So optimizing the production of WCOB give the direction to the researchers and industrialist who are working on waste cooking oil biodiesel. In the present work, the basic model of biodiesel production is taken and the process is optimized with a very effective optimization technique tool. The FFA of waste cooking oil is reduced to $1.3 \%$ through the esterification process and this oil is then used for biodiesel production. As discussed in the last section that 30 experiments are suggested by the design expert software which is performed and the data is fed into the system again. The optimization of all the parameters is conducted by the software with the CCD method and the optimal value of all parameters is provided for maximizing the yield. The optimized value or all parameters are given as catalyst concentration $0.7 \%$, temp. $48^{\circ} \mathrm{C}$, time $41.81 \mathrm{~min}$, molar ratio 7.13 . The yield analyzed by the tool at this condition is $94.2 \%$ 
which is sufficiently higher than what was obtained normally. The fit statistics for the transesterification process represent various important values which are shown in table 3 .

Table 3: Results obtained from ANOVA analysis

\begin{tabular}{|c|c|c|c|c|c|c|}
\hline Source & $\begin{array}{c}\text { Sum of } \\
\text { Squares }\end{array}$ & df & $\begin{array}{l}\text { Mean } \\
\text { Square }\end{array}$ & F-value & p-value & \\
\hline Model & 9594.05 & 14 & 685.29 & 421.30 & $<0.0001$ & \multirow[t]{16}{*}{ significant } \\
\hline A-Catalyst concentration & 824.65 & 1 & 824.65 & 506.97 & $<0.0001$ & \\
\hline B-Reaction temperature & 205.63 & 1 & 205.63 & 126.41 & $<0.0001$ & \\
\hline C-Reaction Time & 129.96 & 1 & 129.96 & 79.90 & $<0.0001$ & \\
\hline D-Molar Ratio & 1387.00 & 1 & 1387.00 & 852.69 & $<0.0001$ & \\
\hline $\mathrm{AB}$ & 299.29 & 1 & 299.29 & 184.00 & $<0.0001$ & \\
\hline $\mathrm{AC}$ & 0.0400 & 1 & 0.0400 & 0.0246 & 0.8775 & \\
\hline $\mathrm{AD}$ & 69.72 & 1 & 69.72 & 42.86 & $<0.0001$ & \\
\hline $\mathrm{BC}$ & 97.02 & 1 & 97.02 & 59.65 & $<0.0001$ & \\
\hline $\mathrm{BD}$ & 40.96 & 1 & 40.96 & 25.18 & 0.0002 & \\
\hline $\mathrm{CD}$ & 9.00 & 1 & 9.00 & 5.53 & 0.0327 & \\
\hline $\mathrm{A}^{2}$ & 1501.99 & 1 & 1501.99 & 923.39 & $<0.0001$ & \\
\hline $\mathrm{B}^{2}$ & 486.72 & 1 & 486.72 & 299.23 & $<0.0001$ & \\
\hline $\mathrm{C}^{2}$ & 958.84 & 1 & 958.84 & 589.47 & $<0.0001$ & \\
\hline $\mathrm{D}^{2}$ & 1486.80 & 1 & 1486.80 & 914.05 & $<0.0001$ & \\
\hline Residual & 24.40 & 15 & 1.63 & & & \\
\hline Lack of Fit & 21.55 & 10 & 2.15 & 3.78 & 0.0778 & $\begin{array}{l}\text { not } \\
\text { significant }\end{array}$ \\
\hline Pure Error & 2.85 & 5 & 0.5707 & & & \\
\hline Cor Total & 9618.45 & 29 & & & & \\
\hline \multicolumn{7}{|c|}{ Fit Statistics } \\
\hline \multirow{2}{*}{$\begin{array}{l}\text { Std. Dev. } \\
\text { Mean }\end{array}$} & 1.28 & & \multicolumn{2}{|l|}{$\mathbf{R}^{2}$} & \multicolumn{2}{|r|}{0.9975} \\
\hline & 73.02 & & \multicolumn{2}{|l|}{ Adjusted R 2} & \multicolumn{2}{|r|}{0.9951} \\
\hline \multirow[t]{2}{*}{ C.V. \% } & 1.75 & & \multicolumn{2}{|c|}{ Predicted R ${ }^{2}$} & \multicolumn{2}{|r|}{0.9867} \\
\hline & & & \multicolumn{2}{|c|}{ Adeq Precision } & \multicolumn{2}{|r|}{67.4089} \\
\hline
\end{tabular}

The yield of WCOB is optimized during this process so that the overall price of biodiesel might be abridged \& quality biodiesel can be produced. To evaluate the fitness of optimization of transesterification process single model of Analysis of variance (ANOVA) is implemented. Total 30 experiments suggested by design experts to appraise possessions of all constraints on maximizing the yield of biodiesel during transesterification are performed.

Consequences are also helpful to understand the sequence of all four parameters in which they affect the biodiesel yield. The reduced quadratic model with good correlations represents the better optimum result for the transesterification process. In the ANOVA result, 
the individual effect of various parameters is given. The higher F-value 421.30of the model is a sign of the significance of the quadratic model. At the same time, a p-value of the model is obtained 0.0001 which is much lower than 0.05 which again shows the significance of the corresponding model term (Noshadi, Amin, \& Parnas, 2012). The higher F-value for all variables shows linear term for these variables for FFA reduction.

However, the p-value for all the parameters remains less than 0.05 for linear as well as quadratic modeling and indicates the significance of the model. Furthermore, the lower Fvalue of 0.0778 for lack of fit indicates that it is not significant as compared to pure error (Wu, Wang, Li, Lin, \& Wei, 2010).

The fit statistics for the transesterification process represent various important values which are also shown in table 3 . In the optimization process, the $\mathrm{R}^{2}$ value of the model represents the variation of the calculated amount around the mean value. The value of $\mathrm{R}^{2}$ in the present steady is 0.9975 which is sufficiently high for showing the significance. However, a higher value of $\mathrm{R}^{2}$ misleads some time that model is significant as its value increase with adding of factors. On the other hand value of the predicted $\mathrm{R}^{2}$ need not increase with adding of factors. The value of predicted $\mathrm{R}^{2}$ during optimizing biodiesel yield is 0.9867 which indicates the model is significant and effective for the transesterification process. Furthermore, the value of adjusted $R^{2}$ is 0.9975 which shows a reasonable agreement with the predicted $R^{2}$ value. The higher value of predicted $\mathrm{R}^{2}$, adjusted $\mathrm{R}^{2}$, and $\mathrm{R}^{2}$ proves that the model is a higher level of significance.

The equation of the optimization process which gives the relationship of all the parameters is given as:

$$
\begin{aligned}
& \text { Yield }=86.1375-19.1444 * \mathrm{~A}-5.85417 * \mathrm{~B}-8.55 * \mathrm{C}+15.2042 * \mathrm{D}-5.76667 * \mathrm{AB}+0.1 \\
& * \mathrm{AC}+2.78333 * \mathrm{AD}+3.69375 * \mathrm{BC}+1.6 * \mathrm{BD}-1.125 * \mathrm{CD}-13.1556 * \mathrm{~A}^{2}-4.2125 * \mathrm{~B}^{2} \\
& -13.3031 * \mathrm{C}^{2}-7.3625 * \mathrm{D}^{2}
\end{aligned}
$$

The adequacy of the model is evaluated by determining the distribution of residuals in the starting. Some deviation in residuals values between predicted and actual can come which 
guides shadow normal distribution only if the model contains random investigational inaccuracies (Körbahti \& Rauf, 2008). Therefore, the externally studentized residual predicted v/s normal $\%$ probability presented in fig. 2 . The presented graph follows a straightforward curve representing externally studentized lingering follow a normal distribution in the model. If the externally studentized residual dissatisfy normal distribution the curve takes the shape of S (Körbahti \& Rauf, 2008). Another graph is plotted between predicted values of yield to the experimental value of yield of biodiesel for particular parameters value

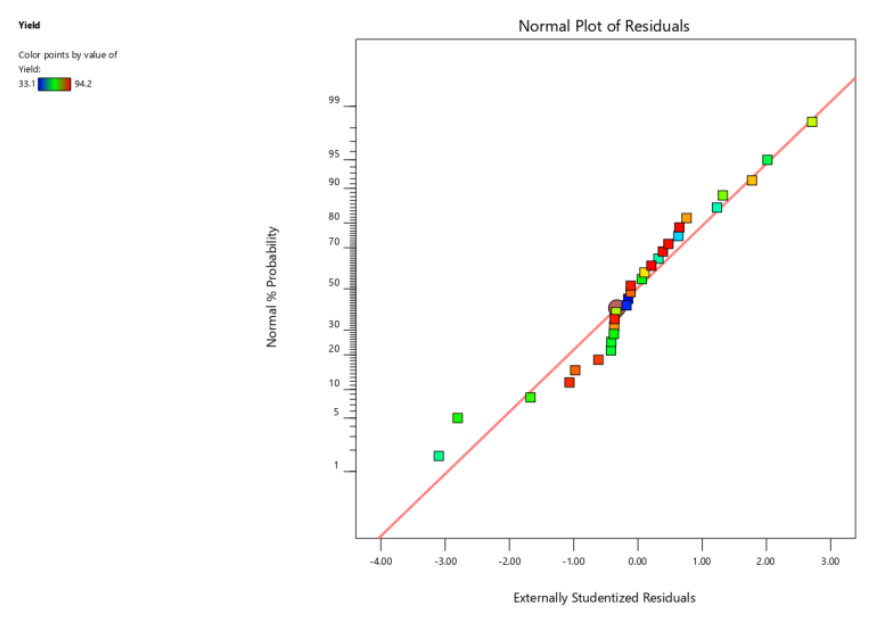

Fig. 2: Externally studentized residuals v/s normal \% probability

The iteration of various variables in three-dimension representation in a combination of each other when the other two variables are fixed for the finest yield of biodiesel production for waste cooking oil represents in fig. 3. The ramp function of the transesterification process conducted to produce biodiesel is presented in fig. 4. Ramp function shows the range of all the variables in which the optimum value is highlighted through a point. This point of all the parameters is considered for optimum process biodiesel production. However, these values are difficult to maintain therefore nearest whole number to the value is considered for the experiment. After the experiment, the yield of WCOB is found near $94 \%$ which again justifies the significance of the model. The final experiment with the optimum value of all parameters is suggested by the design expert. According to the optimizing tool the maximum 
yield of $94.2 \%$ can be possible but experimentally on these parameters the yield of $94 \%$ is achieved.

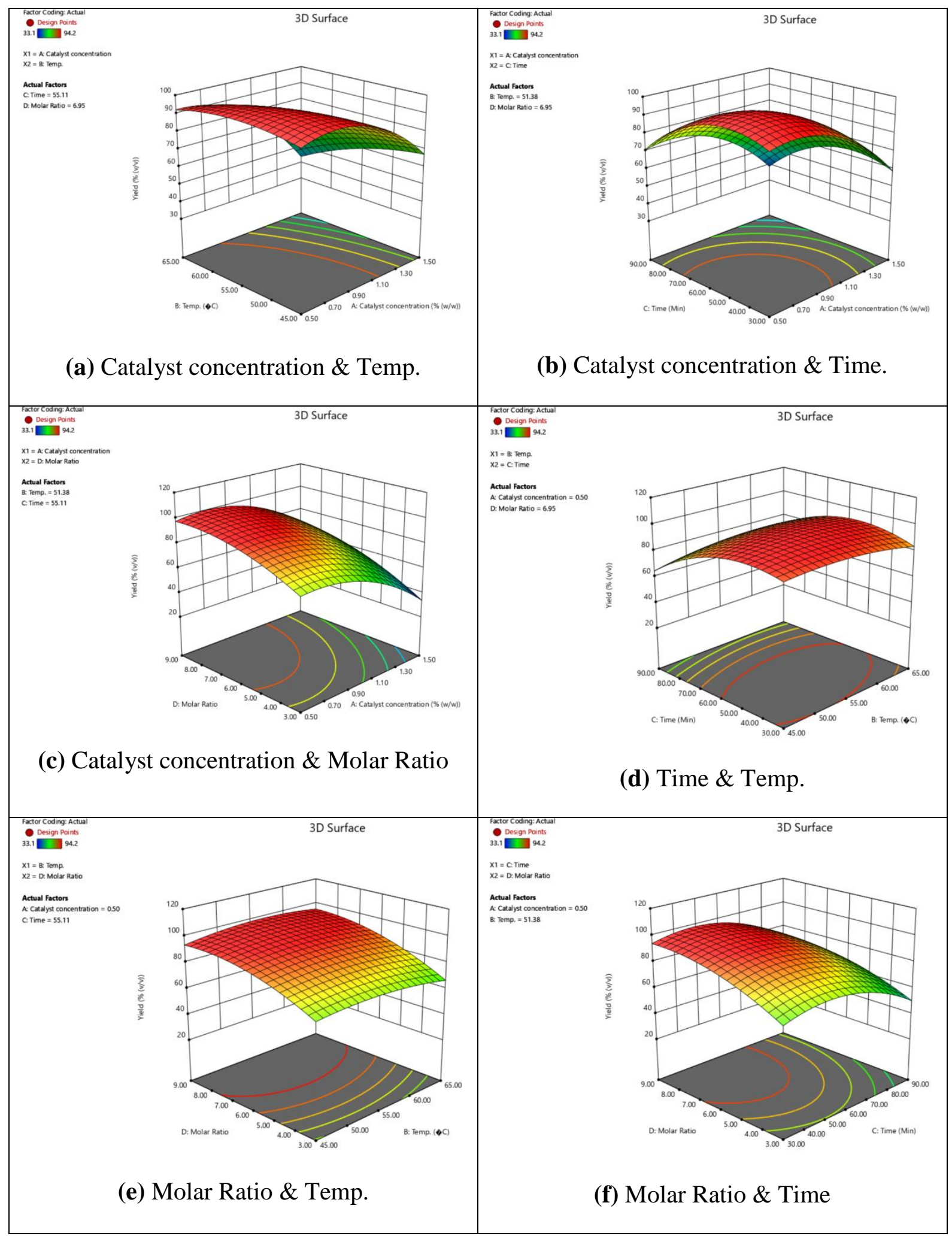

Fig. 3: Effect of various parameters on yield 

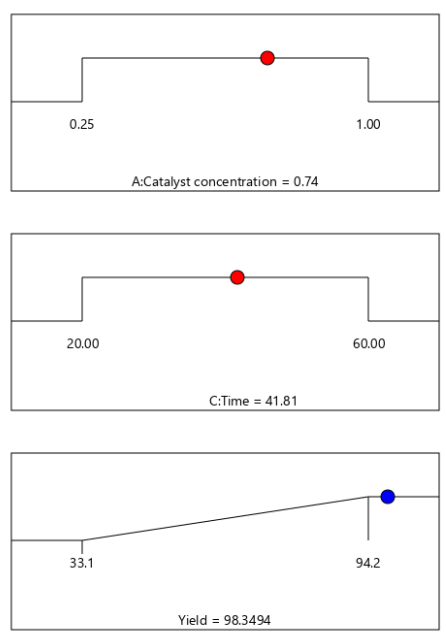

Fig. 4: Ramp function of the transesterification process engines. The biodiesel prepared from waste cooking oil is used in compressed ignition engines after blending with diesel or diesel-like fuel. However, some neat biodiesels can also be used as fuel directly in unmodified or partially modified engines. But most of the biodiesels cannot be used as fuel in unmodified engines due to their properties. So before using biodiesel in the engine its physicochemical properties need to be measured and analyzed. So in the present work as well, the physicochemical properties of normally prepared $\mathrm{WCOB}$ and optimized $\mathrm{WCOB}$ are measured. The measured properties are then compared with petrodiesel fuels to understand the difference between standard fuels and prepared one. All physicochemical properties are measured as per ASTM standards. All properties of tested fuels are measured five-time and the average of all the reading are considered as final value to minimize the error. The value of measured properties of all tested fuels with their measuring standard is given in table 4.

Table 4: Properties of all tested fuels with their measuring standard

\begin{tabular}{|c|c|c|c|c|c|c|c|}
\hline Properties & $\begin{array}{l}\text { Name of } \\
\text { Equipment }\end{array}$ & Make & $\begin{array}{l}\text { ASTM } \\
\text { Standard }\end{array}$ & $\begin{array}{l}\text { Operating } \\
\text { Range }\end{array}$ & Diesel & $\begin{array}{l}\text { Normal } \\
\text { WCOB }\end{array}$ & $\begin{array}{l}\text { Optimized } \\
\text { WCOB }\end{array}$ \\
\hline $\begin{array}{l}\text { Density } \\
\left(\mathrm{g} / \mathrm{cm}^{3}\right)\end{array}$ & DMA 4500 & Anton Paar & D4052 & $\begin{array}{l}0 \mathrm{~g} / \mathrm{cm}^{3} \text { to } \\
1.5 \mathrm{~g} / \mathrm{cm}^{3}\end{array}$ & 0.823 & 0.878 & 0.871 \\
\hline $\begin{array}{l}\text { Kinematic } \\
\text { Viscosity } \\
\left(\mathrm{mm}^{2} / \mathrm{s}\right)\end{array}$ & $\begin{array}{l}\text { Capillary } \\
\text { Viscosity - } \\
\text { High } \\
\text { Temperature }\end{array}$ & Petrotest & D445 & $\begin{array}{l}+5^{\circ} \mathrm{C} \text { to } \\
+150^{\circ} \mathrm{C}\end{array}$ & 2.6 & 4.6 & 4.4 \\
\hline Calorific & Bomb & Parr & D240 & 52 to & 43.6 & 40.9 & 41.1 \\
\hline
\end{tabular}




\begin{tabular}{|l|l|l|l|l|l|l|l|}
\hline $\begin{array}{l}\text { Value } \\
(\mathrm{MJ} / \mathrm{kg})\end{array}$ & Calorimeter & & & $\begin{array}{l}12000 \\
\text { calorie }\end{array}$ & & & \\
\hline $\begin{array}{l}\text { Flash Point } \\
\left({ }^{\circ} \mathrm{C}\right)\end{array}$ & $\begin{array}{l}\text { Automatic } \\
\text { Flashpoint } \\
\text { Tester }\end{array}$ & $\begin{array}{l}\text { Pensky } \\
\text { Martens }\end{array}$ & D93 & $\begin{array}{l}\text { up to } 405 \\
{ }^{\circ} \mathrm{C}\end{array}$ & 54 & 196 & 192 \\
\hline $\begin{array}{l}\text { Cold Filter } \\
\text { pluging } \\
\text { Point }\left({ }^{\circ} \mathrm{C}\right)\end{array}$ & $\begin{array}{l}\text { CFPP } \\
\text { METER }\end{array}$ & $\begin{array}{l}\text { Linetronic } \\
\text { Technologies }\end{array}$ & D6371 & $\begin{array}{l}-40^{\circ} \mathrm{C} \text { to } \\
50^{\circ} \mathrm{C}\end{array}$ & $-12^{\circ} \mathrm{C}$ & $1{ }^{\circ} \mathrm{C}$ & $-2^{\circ} \mathrm{C}$ \\
\hline $\begin{array}{l}\text { Cetane } \\
\text { Index }\end{array}$ & $\begin{array}{l}\text { Four Variable } \\
\text { Method }\end{array}$ & & D4737 & & 45 & 54 & 54 \\
\hline
\end{tabular}

It can be seen from table 4, that all the measured properties of normal WCOB and optimized WCOB are very much comparable to the petrodiesel accept kinematic viscosity which is slightly higher but is the range as per ASTM standard D6751 which defines the biodiesel quality. However, by seeing the property table it can be analyzed that the quality of optimized WCOB is better than normal WCOB. Most of the properties of optimized WCOB are better compared to normal WCOB or equal. Hence it can be easily analyzed that the optimization of biodiesel production for waste cooking oil not only improves the yield but also improves the properties of the end product.

\section{CONCLUSIONS}

In the present work, the biodiesel prepared from waste cooking oil is optimized through the central composite design of the response surface methodology technique. Some important conclusions are drawn from the present work which is as follows:

- The CCD approach for optimization gives better results in a limited number of experiments by establishing a good relationship between all parameters.

- The yield of WCOB is increased from $94 \%$ to $98 \%$ which is sufficiently higher.

- The yield of $98 \%$ for WCOB is achievable by considering catalyst concentration of 0.74 , Temp. $48^{\circ} \mathrm{C}$, Time $41.83 \mathrm{~min}$ and the molar ratio of 7.3 . The agitation speed is kept constant at $300 \mathrm{rpm}$.

- The physicochemical properties of optimized WCOB are found better than normally prepared WCOB. 


\section{REFERENCES}

Bellotti, D., Cassettari, L., Mosca, M., \& Magistri, L. (2019). RSM approach for stochastic sensitivity analysis of the economic sustainability of a methanol production plant using renewable energy sources. Journal of Cleaner Production, 240, 117947. https://doi.org/10.1016/j.jclepro.2019.117947

British Petroleum. (2019). BP Energy Outlook 2019 edition The Energy Outlook explores the forces shaping the global energy transition out to 2040 and the key uncertainties surrounding that. BP Energy Outlook 2019.

Chaudhary, V., \& Gakkhar, R. P. (2019). Exergy analysis of small DI diesel engine fueled with waste cooking oil biodiesel. Energy Sources, Part A: Recovery, Utilization and Environmental Effects, O0(00), 1-15. https://doi.org/10.1080/15567036.2019.1624875

Demirbas, A. (2009). Characterization of biodiesel fuels. Energy Sources, Part A: Recovery, Utilization and Environmental Effects, 31(11), 889-896.

https://doi.org/10.1080/15567030801904202

Demirbas, A. (2010). Biodiesel for future transportation energy needs. Energy Sources, Part A: Recovery, Utilization and Environmental Effects, 32(16), 1490-1508. https://doi.org/10.1080/15567030903078335

Dinkar, S. K., \& Deep, K. (2019). Process optimization of biodiesel production using antlion optimizer. Journal of Information and Optimization Sciences, 40(6), 1281-1294. https://doi.org/10.1080/02522667.2018.1491821

Ghadge, S. V., \& Raheman, H. (2006). Process optimization for biodiesel production from mahua (Madhuca indica) oil using response surface methodology. Bioresource Technology, 97(3), 379-384. https://doi.org/10.1016/j.biortech.2005.03.014

Karthikeyan, M., Renganathan, S., \& Baskar, G. (2017). Production of biodiesel from waste cooking oil using $\mathrm{MgMoO} 4$-supported $\mathrm{TiO} 2$ as a heterogeneous catalyst. Energy Sources, Part A: Recovery, Utilization and Environmental Effects, 39(21), 2053-2059. https://doi.org/10.1080/15567036.2017.1371815

Knothe, G., \& Razon, L. F. (2017). Biodiesel fuels. Progress in Energy and Combustion Science, 58, 36-59. https://doi.org/10.1016/j.pecs.2016.08.001

Körbahti, B. K., \& Rauf, M. A. (2008). Response surface methodology (RSM) analysis of photoinduced decoloration of toludine blue. Chemical Engineering Journal, 136(1), 2530. https://doi.org/10.1016/j.cej.2007.03.007

Kumar, M., \& Sharma, M. P. (2016). Selection of potential oils for biodiesel production. Renewable and Sustainable Energy Reviews, 56, 1129-1138. https://doi.org/10.1016/j.rser.2015.12.032

Kumar, N., Mohapatra, S. K., Ragit, S. S., Kundu, K., \& Karmakar, R. (2017). Optimization of safflower oil transesterification using the Taguchi approach. Petroleum 
Science, 14(4), 798-805. https://doi.org/10.1007/s12182-017-0183-0

Kumar, Naveen, \& Sidharth. (2018). Some Studies on use of ternary blends of diesel, biodiesel and n-octanol. Energy Sources, Part A: Recovery, Utilization and Environmental Effects, 40(14), 1721-1728. https://doi.org/10.1080/15567036.2018.1486902

Kumar, P., \& Kumar, N. (2016). Experimental investigation of Jatropha oil methyl ester (JOME) as pilot fuel with CNG in a dual fuel engine. Biofuels, 7(5), 511-520. https://doi.org/10.1080/17597269.2016.1163215

Kumar, P., \& Kumar, N. (2019). Environmental Effects Process optimization for production of biodiesel from orange peel oil using response surface methodology. Energy Sources, Part A: Recovery, Utilization, and Environmental Effects, O(0), 1-11. https://doi.org/10.1080/15567036.2019.1631909

Mirjalili, S. (2015). The ant lion optimizer. Advances in Engineering Software, 83, 80-98. https://doi.org/10.1016/j.advengsoft.2015.01.010

Noshadi, I., Amin, N. A. S., \& Parnas, R. S. (2012). Continuous production of biodiesel from waste cooking oil in a reactive distillation column catalyzed by solid heteropolyacid: Optimization using response surface methodology (RSM). Fuel, 94, 156-164. https://doi.org/10.1016/j.fuel.2011.10.018

Pali, H. S., Kumar, N., \& Alhassan, Y. (2015). Performance and emission characteristics of an agricultural diesel engine fueled with blends of Sal methyl esters and diesel. Energy Conversion and Management, 90, 146-153. https://doi.org/10.1016/j.enconman.2014.10.064

Raheman, H., \& Phadatare, A. G. (2004). Diesel engine emissions and performance from blends of karanja methyl ester and diesel. Biomass and Bioenergy, 27(4), 393-397. https://doi.org/10.1016/j.biombioe.2004.03.002

Rosa, H., Tropecêlo, A. I., Caetano, C. S., \& Castanheiro, J. E. (2015). Valorization of waste cooking oil into biodiesel over an anionic resin as catalyst. Energy Sources, Part A: Recovery, Utilization and Environmental Effects, 37(21), 2309-2316. https://doi.org/10.1080/15567036.2011.609864

Saravanakumar, A., Avinash, A., \& Saravanakumar, R. (2016). Optimization of biodiesel production from Pungamia oil by Taguchi'stechnique. Energy Sources, Part A:

Recovery, Utilization and Environmental Effects, 38(17), 2524-2529. https://doi.org/10.1080/15567036.2015.1098746

Sidharth, \& Kumar, N. (2019). Performance and emission studies of ternary fuel blends of diesel, biodiesel and octanol. Energy Sources, Part A: Recovery, Utilization and Environmental Effects, O(00), 1-20. https://doi.org/10.1080/15567036.2019.1607940 
Sonthalia, A., \& Kumar, N. (2019). Hydroprocessed vegetable oil as a fuel for transportation sector: A review. Journal of the Energy Institute, 92(1), 1-17. https://doi.org/10.1016/j.joei.2017.10.008

Verma, P., \& Sharma, M. P. (2016). Comparative analysis of effect of methanol and ethanol on Karanja biodiesel production and its optimisation. Fuel, 180, 164-174. https://doi.org/10.1016/j.fuel.2016.04.035

Wu, J., Wang, J. Le, Li, M. H., Lin, J. P., \& Wei, D. Z. (2010). Optimization of immobilization for selective oxidation of benzyl alcohol by Gluconobacter oxydans using response surface methodology. Bioresource Technology, 101(23), 8936-8941. https://doi.org/10.1016/j.biortech.2010.07.019 